\title{
'SHOULD NST' - An alternative to MUST for nutritional screening in long stay (average 8 years) mental health patients
}

\author{
Frances. M. Waddell and A. Joy Farquharson \\ The State Hospital, Carstairs, Scotland
}

Nutritional screening has been identified as an essential component of patient care (Scottish Executive 2003 ${ }^{(1)}$, BAPEN 2010 ${ }^{(2)}$ ) Individuals with mental health illnesses have significantly higher rates of chronic diseases such as diabetes and coronary heart disease than the general population (Davidson et al. 2001 ${ }^{(3)}$, Prince et al. $2007^{(4)}$, Isenring $2008^{(5)}$ ), in addition to a higher prevalence of smoking, physical inactivity, overweight and obesity and high levels of alcohol and salt intake (Sharpe \& Hills $1998^{(6)}$, Elmslie et al. 2000 ${ }^{(7)}$, Davidson et al. $2001^{(3)}$, Marder et al. $2004^{(8)}$ ). Adverse health related risk factors for mental health patients include obesity, antipsychotic medication, smoking, drugs, alcohol, low social economic status, disordered eating, overall poor physical health, lack of employment and motivation (Thomas B 2007) ${ }^{(9)}$. Nutritional screening has been promoted to help decrease rates of malnutrition. The Quality Improvement Scotland Standards for Food, Fluid and Nutritional Care in Hospitals $\left(2003^{(1)}\right)$ state that all patients must be nutritional screened using a validated tool upon admission and on an ongoing basis. More recently 'Realising Potential' The Action Plan for Allied Health Professional's working in Mental Health (SG 2010) ${ }^{(10)}$ reiterates the importance of nutritional screening.

Nutritional screening is a key requirement of the QIS Food, Fluid and Nutritional Care Standards and in preparation for the 2009 review consideration was given to the use of the nationally recognised, validated screening tool, MUST (BAPEN 2003) ${ }^{(11)}$. Following a robust review of MUST, an exploratory project was undertaken in a High Secure Psychiatric Hospital in Scotland to audit the results of MUST used along side a local developed nutritional screening tool (State Hospital, Overweight, Underweight, Learning Disability (SHOULD) NST) which includes potential risk factors relating to malnutrition likely in long stay mental health patients.

Twenty four patients were nutritionally screened using both tools by one of the authors. The results were analysed and showed that MUST only identified two patients at nutritional risk in comparison to the local tool which identified 13 patients as being at nutritional risk. The 13 patients identified by SHOULD, included the 2 underweight patients identified by MUST and identified a further 11 who had a variety of nutritional risks including; Disordered Eating, Obesity (inc inappropriate nourishment) Physical health conditions requiring a therapeutic diet, Physical illness, disease or treatment, Dysphasia and/or were prescribed high doses of know weight inducing Antipsychotics.

Following this exploratory audit and careful consideration of the results, the hospital decided to undertake the validation of 'SHOULD' as a more appropriate tool for undertaking nutritional screening of long stay mental health patients. An extensive validation exercise has been undertaken and will be published in due course. 'SHOULD' is currently implemented across the hospital where the author's practice and an internal audit undertaken one year after implementation confirmed that it is indentifying patients at nutritional risk.

1. Scottish Executive (2003) Food, Fluid and Nutritional Care in Hospitals.

2. BAPEN (2010) Nutritional Screening Survey in the UK and republic of Ireland in 2010, including Hospitals, care homes and mental health units.

3. Davidson S, Judd F, Jolley D, Hocking B, Thompson S \& Hyland B (2001) Cardiovascular Risk Factors for People with Mental Illness. Australian and New Zealand Journal of Psychiatry 35, 196-202.

4. Prince M, Vikram Patel SS, Maj M, Maselko J, Philips MR \& Rahman A (2007) No Health without Mental Health. The Lancet 370, 859-77.

5. Isenring E (2008) Nutrition and Mental Health Research: Where to from here? Nutrition \& Dietetics 65, 4-5.

6. Sharpe, Jenny-Kay \& Andrew P Hills (1998) Anthropometry and Adiposity in a Group of People with Chronic Mental Illness. Australian and New Zealand Journal of Psychiatry 32, 77-81.

7. Elmslie JL, Silverstone JT, Mann JI, Williams SM \& Romans SE (2000) Prevalence of overweight and obesity in bipolar patients. Journal of Clinical Psychiatry, 61, 179-184

8. EMarder SR, Essock SM \& Miller AL (2004) Physical Health Monitoring ofPatients with Schizophrenia. American Journal of Psychiatry 161, $1334-49$

9. EThomas B (2007) Manual of Dietetic Practice. Blackwell Publishing. Chp 4.31

10. EScottish Government (2010) 'Realising Potential' an action plan for AHP in mental health

11. EBAPEN (2003) Malnutrition Universal Screening Tool (MUST). 